\title{
COMMENTARY
}

\section{Long-term results of the surgical treatment of Peyronie's disease with plaque incision and grafting}

\author{
David J Ralph \\ Asian Journal of Andrology (2011) 13, 797; doi:10.1038/aja.2011.117; Published online: 25 July 2011
}

$\mathrm{P}$ eyronie's disease is frequently associated with erectile dysfunction, and a variety of other comorbid disorders, including diabetes, hypertension, dyslipidemia and low testosterone. Two-thirds of patients with Peyronie's disease are likely to have risk factors for arterial disease and therefore worsening long-term erectile function. ${ }^{1}$ The severe emotional distress that occurs is, in part, due to the deformity, but mainly due to the penile shortening that occurs in almost all patients with up to $50 \%$ of them being clinically depressed. It is imperative therefore that the stretched penile length is measured preoperatively so that the patients realize that the length loss postoperatively is mainly due to the disease itself and not to the surgery. ${ }^{2,3}$

Patients that have significant deformities often desire a grafting procedure that minimizes any additional length loss. Currently, it appears that the nature of the graft is less likely the determining factor with respect to postoperative erectile dysfunction (ED). On the other hand, it is most likely due to patient selection with respect to preoperative erectile status and operative technique. ${ }^{4}$ Larger grafts, men older than 60 years old, and those with ventral grafting also appear to have a higher risk of postoperative ED.,

Following surgery, postoperative rehabilitation is recommended to enhance recovery of erectile function. Massage and stretch therapy, is performed by grasping the glans penis and pulling it gently and repeatedly away from the body while also gently massaging the graft area. Daily phosphodiesterase inhibitors have been recommended to begin 7-10 days after surgery and to be maintained for 6 weeks, in order to enhance nocturnal erections, stretch the tissue, encourage nourishment of the graft ${ }^{4}$ and possibly reduce the risk of postoperative ED. Finally, the use of

Institute of Urology, London, UK

Correspondence: Dr DJ Ralph (dralph@andrology.co.uk) external penile traction therapy has been noted to reduce postoperative penile shortening for patients who have undergone either plication or grafting procedures. $^{7}$

The results from published reports on grafting show that on average $74 \%-100 \%$ of patients were adequately straight, with a postoperative ED ranging from $5 \%$ to $53 \% .^{8}$ Recently, a report by Sansalone et al. ${ }^{9}$ was published in Asian Journal of Andrology. This is an interesting article of the management of Peyronie's disease using the Egydio technique of plaque incision and grafting. The technique has been tried and tested before and is proven to straighten the penis without the use of plication sutures which cause penile shortening. ${ }^{10}$ The results of this series are outstanding and the reason for this is case selection.

With the knowledge that erectile function may deteriorate over time, the results at 5-year follow-up should be considered. Kalsi et al. ${ }^{11}$ studied 40 patients who underwent vein grafting and followed for at least 5 years and reported a postoperative ED rate of $22.5 \%$ and a loss of length was noted in $35 \%$. Montorsi et al. ${ }^{12}$ reported on 50 patients with a 5-year followup after venous grafting where there was either persistent or recurrent curvature in $12 \%$, length loss in $100 \%$, postoperative ED in $22 \%$, diminished orgasm in $41 \%$ and overall patient satisfaction of only $60 \%$. The poor results in all other series are related to post operative $\mathrm{ED}$, reaching $67 \%$ in one series. ${ }^{13}$ In the Sansalone series, only patients with good preoperative erectile function were included (International Index of Erectile Function $>15$, peak systolic velocity $>35 \mathrm{~cm}$ $\left.\mathrm{s}^{-1}\right)$, the others offered a penile prosthesis. Despite this, 32\% did develop postoperative ED and were treated with phosphodiesterase type 5 inhibitors, but as least the authors tried to streamline patients to get better satisfaction results. ${ }^{9}$

The take home message is that this technique has a high success rate in advanced Peyronie's disease and that patient selection is crucial. It may be that in the future, patients should have even higher preoperative erectile function parameters to improve on these results further.

1 Kadioglu A, Tefekli A, Erol B, Oktar T, Tunc M et al. A retrospective review of 307 men with Peyronie's disease. J Urol 2002; 68: 1075-9.

2 Smith JF, Walsh TJ, Conti SL, Turek P, Lue T. Risk factors for emotional and relationship problems in Peyronie's disease. J Sex Med 2008; 5: 2179-84.

3 Nelson CJ, Diblasio C, Kendirci M, Hellstrom W, Guhring $\mathrm{P}$ et al. The chronology of depression and distress in men with Peyronie's disease. J Sex Med 2008; 5: 1985-90.

4 Levine LA, Greenfield JM, Estrada CR Erectile dysfunction following surgical correction of Peyronie's disease and a pilot study of the use of Sildenafil citrate rehabilitation for postoperative erectile dysfunction. J Sex Med 2007; 5: 241-7.

5 Mulhall JP, Anderson M, Parker M. A surgical algorithm for men with combined Peyronie's disease and erectile dysfunction: functional and satisfaction outcomes. J Sex Med 2005; 2: 132-8.

6 Flores S, Choi JM, Alex B, Mulhall J. Erectile dysfunction after plaque incision and grafting: short term incidence and predictors. I Sex Med; e-pub ahead of print 19 May 2011; doi:10.1111/j.17436109.2011.02299.x.

7 Gontero P, Di Marco M, Giubilei G, Bartoletti R, Pappagallo $\mathrm{G}$ et al. Use of penile extender device in the treatment of penile curvature as a result of Peyronie's disease. Results of a phase II prospective study. J Sex Med 2009; 6: 559-566.

8 Ralph D, Gonzalez-Cadavid N, Mirone V, Perovic S, Sohn $M$ et al. The management of Peyronie's disease: evidence based guidelines. J Sex Med 2010; 7: 2359-74.

9 Sansalone S, Garaffa G, Djinovic R, Pecoraro S, Silvani $\mathrm{M}$ et al. Long-term results of the surgical treatment of Peyronie's disease with Egydio's technique: a European multicentre study. Asian J Androl; e-pub ahead of print 11 July 2011; doi:10.1038/aja.2011.42.

10 Egydio PH, Lucon AM, Arap S. A single relaxing incision to correct different types of penile curvature: surgical technique based on geometrical principles. BJU Int 2004; 94: 1147-57.

11 Kalsi J, Minhas S, Christopher N, Ralph D. The results of plaque incision and venous grafting (Lue procedure) to correct the penile deformity of Peyronie's disease. BJU Int 2005; 95: 1029-33.

12 Montorsi F, Salonia A, Briganti A, Dehò F, Zanni G et al. Five year follow-up of plaque incision and vein grafting for Peyronie's disease. J Urol 2004; 171: 331.

13 Cheung E, Clindinning E, Lessard L, Brock G. Five-year follow up of Peyronie's graft surgery: outcomes and patient satisfaction. J Sex Med 2011; 8: 594-600. 